\title{
Testosterone-receptor positive hepatocellular carcinoma in a 29-year old bodybuilder with a history of anabolic androgenic steroid abuse: a case report
}

\author{
Philipp Solbach ${ }^{1 *}$, Andrej Potthoff', Hans-Jürgen Raatschen², Bisharah Soudah ${ }^{3}$, Ulrich Lehmann $^{3}$, \\ Andrea Schneider ${ }^{1}$, Michael J. Gebel ${ }^{1}$, Michael P. Manns ${ }^{1}$ and Arndt Vogel ${ }^{1}$
}

\begin{abstract}
Background: Continuous use of anabolic androgenic steroid in high-doses is associated with substantial health risks, including hepatocellular adenoma. Malignant transformation from hepatocellular adenoma to hepatocellular carcinoma after anabolic androgenic steroid abuse has been rarely reported. The morphological distinction of adenoma from well-differentiated hepatocellular carcinoma is challenging and requires elaborated imaging techniques and histology.

Case presentation: We report about a 29-year old male professional bodybuilder who presented with mid-epigastric pain at the emergency unit. Ultrasound showed a severe hepatomegaly with multiple lesions. Contrast-enhanced ultrasound revealed a heterogeneous pattern with signs of hepatocellular carcinoma. CT scan of the abdomen confirmed multiple hypervascular lesions and central areas of necrosis without contrast enhancement. Subsequent diagnostics included fine needle aspiration (FNA) of suspicious lesions and mini-laparoscopy to establish the diagnosis of a $\beta$-catenin and testosterone-receptor positive hepatocellular carcinoma embedded in multiple adenomas. The patient was subsequently treated by liver transplantation and remains tumor-free 27 month after surgery.

Conclusion: Hepatocellular carcinoma occurring in association with anabolic androgenic steroid abuse should sensitize
\end{abstract} physicians and especially professional bodybuilders for the harmful use of high doses of steroids.

Keywords: Anabolic androgenic steroids, Hormonal treatment, Hepatocellular carcinoma, Hepatic adenoma

\section{Background}

One of the major risk factors of developing hepatocellular adenoma (HCA) is the use of oral contraceptives, which stimulate liver expressed estrogen and androgen receptors, predominantly in women between 15 and 45 years of age $[1,2]$. Accordingly, $90 \%$ of $\mathrm{HCA}$ are diagnosed in women [3]. Other risk factors include glycogen storage disease I and III and treatment with anabolic steroids in patients with Fanconi's anemia [4-6]. A few reports indicate that anabolic androgenic steroids (AAS)

\footnotetext{
* Correspondence: solbach.philipp@mh-hannover.de

'Department of Gastroenterology, Hepatology and Endocrinology, Medizinische Hochschule, OE 6810 Carl-Neuberg-Str. 1, 30625 Hannover Germany

Full list of author information is available at the end of the article
}

may also lead to the formation of HCA [7-9]. Relevant complications of HCA include hemorrhage and malignant transformation into hepatocellular carcinoma (HCC) depending on size and $\beta$-catenin activation.

In the literature are more reports of patients with Fanconi's anemia, which received medical treatment with AAS and subsequently developed HCCs $[4,6]$. Furthermore a few cases are described from bodybuilders with AAS abuse that subsequently developed $\operatorname{HCC}[7,9,10]$. These patients require close surveillance to detect possible malignant transformation from HCA into HCC or lesions that are at risk of bleeding or rupture [8].

Here, we report a case of a testosterone-receptor positive $\mathrm{HCC}$ arising from multiple HCAs in a professional 
bodybuilder after 6 years of AAS abuse and the difficulties of diagnostics and therapeutical options.

\section{Case presentation Clinical history}

We describe a case of a 29-year old male professional bodybuilder who presented at the emergency unit with midepigastric-pain. He had been taking anabolic androgenic steroids (AAS; see below) and underwent strict nutritional diets to increase muscle mass prior to competitions over the last 6 years. He self-administered the following AAS from 2011 to 2012 in cycles of 4 weeks with rest periods of several weeks between the cycles: nandrolone decanoate (400 mg/week), sustanon (750 mg/ week), methandienone (280-350 mg/week), stanozolol (50 mg/day for 1 month) and human growth hormone (4 IE/day for 3 month). Additionally 3 days before competitions he self-administered the diuretics aldosterone (50 mg/day) and thiazide ( $25 \mathrm{mg} /$ day) to reduce extracellular and subcutaneous tissue volume and to achieve a better muscle shaping. Furthermore insulin injections and tamoxifen were administered. The frequency of selfadministration was varying in each cycle.

At presentation, the patient had not taken any AAS for 5 weeks. Previous history was a childhood near a nuclear power plant until the age of fifteen. Allergic coryza and nasal spray use since the age of seven were reported. Moreover no abuse of ethanol or smoking was given. The patient's father died supposedly as the result of kidney cancer, his grandfather died from bronchial cancer. His mother and younger siblings are healthy. On examination, the patient showed a three-fold amplified liver extending into lesser pelvis with painful palpation. No other clinical abnormalities were detectable (Fig. 1).

\section{Laboratory findings}

Laboratory evaluation revealed severe hepatic inflammation and an impaired liver function (ALT 1653 IU/l; AST 1437 IU/l; alkaline phosphatase 372 IU/l; GGT 463 IU/l; CHE 1.29 kU/I; LDH 695 U/I; total bilirubin $41 \mu \mathrm{mol} / \mathrm{l}$; direct bilirubin $38 \mu \mathrm{mol} / \mathrm{l})$. Hematology showed an anemia and slightly increased white blood cell count (leucocytes 12.500/ $\mu \mathrm{l}$; hemoglobin $8.5 \mathrm{~g} / \mathrm{dl}$; INR 1.04; reticulocytes $104 / \mathrm{nl}$ ). Inflammation parameters were increased (CRP $81 \mathrm{mg} / \mathrm{l}$, PCT $4.8 \mu \mathrm{g} / \mathrm{l}$, Ferritin $1672 \mu \mathrm{g} / \mathrm{l})$. The renal function was almost normal (creatinine $123 \mu \mathrm{mol} / \mathrm{l}$, but cystatine c $0.76 \mathrm{mg} / \mathrm{l}$ and MDRD $>60 \mathrm{ml} / \mathrm{min}$ ).

Coagulation tests were normal, as well as hepatitis virus markers, including hepatitis $\mathrm{A}, \mathrm{B}$ and $\mathrm{C}$ and also human deficiency virus markers were negative. Serum levels of sex hypophyseal hormones ( $\mathrm{LH}<0.07 \mathrm{U} / \mathrm{I}, \mathrm{FSH}$ $<0.3 \mathrm{U} / \mathrm{I}$, androgens ( $\mathrm{T}+\mathrm{DHT}) \quad 0.037 \mathrm{ng} / \mathrm{ml}$, freetestosterone $4.94 \mathrm{pg} / \mathrm{ml}$ ) and thyroid gland markers (fT3, fT4) were below the lower limit of normal. This constellation of sex hormones reflects anabolic steroids induced hypogonadism (ASIH).

\section{Imaging}

Abdominal ultrasound (US) showed a marked hepatomegaly with $25.6 \mathrm{~cm}$ in the midclavicular line and $30.1 \mathrm{~cm}$ in the median with evidence of fatty liver. In B-mode sonography multiple lesions were detected in both liver lobes (left liver lobe: various isoecogenic, inhomogeneous lesions with a maximum size of $92 \mathrm{~mm} \times 92 \mathrm{~mm}$; right liver lobe: various isoecogenic, polycyclic inhomogeneous lesions with a maximum size of $222 \mathrm{~mm} \times 162 \mathrm{~mm}$ ) (Fig. 2a). Moreover, the hepatic segment of the inferior vena cava (IVC) was compressed by the hepatic tumors, which consecutively led to a partial Budd Chiari syndrome. This was
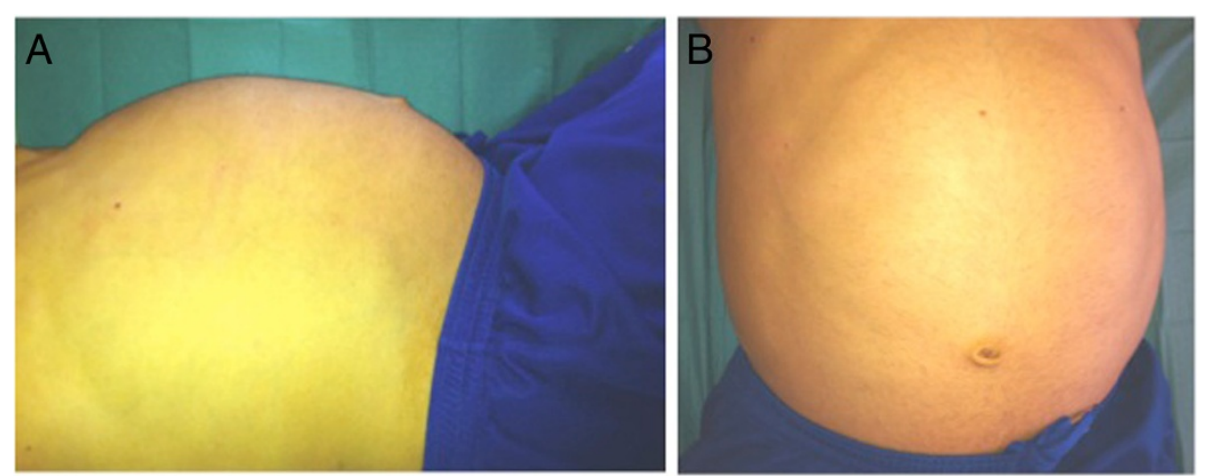

Fig. 1 Clinical examination showed a muscular body, height $186 \mathrm{~cm}$, weight $120 \mathrm{~kg}$. The lung showed a sonorous percussion, vesicular breath sounds, no noise. Heart: regular rhythm, 55 bpm, RR 134/67 mmHg, first heart sound and second heart sound not flashy, no heart murmurs. No pathological examination findings for head, neck, lymph node status, pulse status. No scleral icterus. Abdominal examination showed a large abdomen, vascular abdominal markings, yellow colouring, liver palpable to lesser pelvis right, superficial palpation was painful, spleen not palpable, no kidney pain or back pain (a lateral view; b ventral view) 

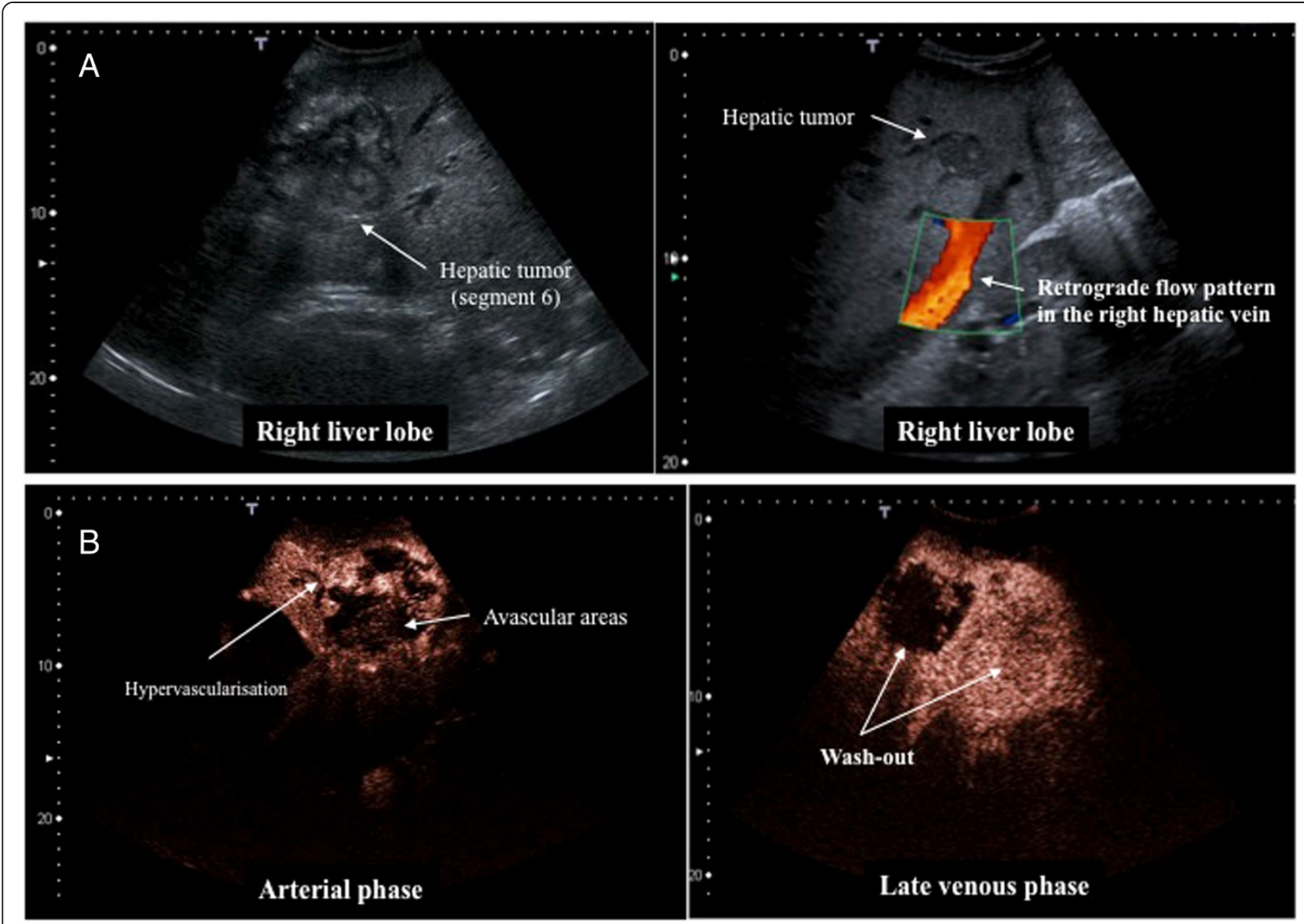

Fig. 2 a B-mode ultrasonography: The hepatic tumors were polycyclic, isoechoic and inhomogeneous. Doppler sonography showed a compression in the IVC hepatic segment by the liver tumors with consecutive development of partial Budd Chiari syndrome diagnosed by the retrograde flow pattern in the right hepatic vein and the presence of subcapsular venous collaterals. b Contrast enhanced ultrasonography (CEUS): CEUS was performed using a bolus injection of $1.5 \mathrm{~mL}$ SonoVue ${ }^{\circledast}$ (Bracco SpA, Milan, Italy). The largest lesion showed a large, avascular center with hypervascular margin in the arterial phase. In the late venous phase parts of the center and the margin showed wash-out

diagnosed in the doppler sonography through the retrograde flow pattern in the right hepatic vein with an evidence of subcapsular venous collaterals.

In contrast-enhanced ultrasound (CEUS) the hepatic lesions showed a heterogeneous pattern (Fig. 2b). Some lesions exhibited arterial enhancement, initially at the periphery with subsequent very rapid centripetal filling and without wash-out in the portal venous or late phase. Other lesions showed arterial enhancement, with a chaotic vascular pattern and avascular areas in different parts of each tumor. In the portal venous phase, these tumors showed wash-out, especially in liver segment 6, in which a tumor biopsy was performed. The small lesions (diameter $<12 \mathrm{~mm}$ ) seen in B-mode sonography showed neither arterial hypervascularisation nor washout in the portal venous or late phase. The contrastenhanced CT scan of the abdomen revealed a distinctive hepatomegaly with multiple hypervascular lesions without substantial wash-out in portal venous phase. In the largest lesions, central areas of necrosis without contrast enhancement were present $(16 \times 13 \mathrm{~cm})$ (Fig. 3). There was no evidence of metastasis in the abdomen and chest.

\section{Pathology}

Cytology of liver-segment six was performed by fine needle aspiration (FNA) of one lesion with signs of hepatocellular carcinoma in contrast-enhanced ultrasound. The cytological samples did not reveal malignancy and showed no clearly signs for hepatocellular carcinoma or hepatoblastoma. Further molecular cytogenetic and pathologicalanatomical diagnostics showed atypical HCA.

To confirm the diagnosis of hepatocellular carcinoma in suspicious lesions, a diagnostic laparoscopy was performed. The liver was enormously enlarged and there was almost no veritable parenchyma visible between the tumor nodules. The largest tumors bulged out of the liver's surface with yellow to bluish discoloration and strong tumor vascular markings. Biopsy of the liver in the right lobe from three tumors and one tumor of the left lobe was performed. The synopsis of morphology 

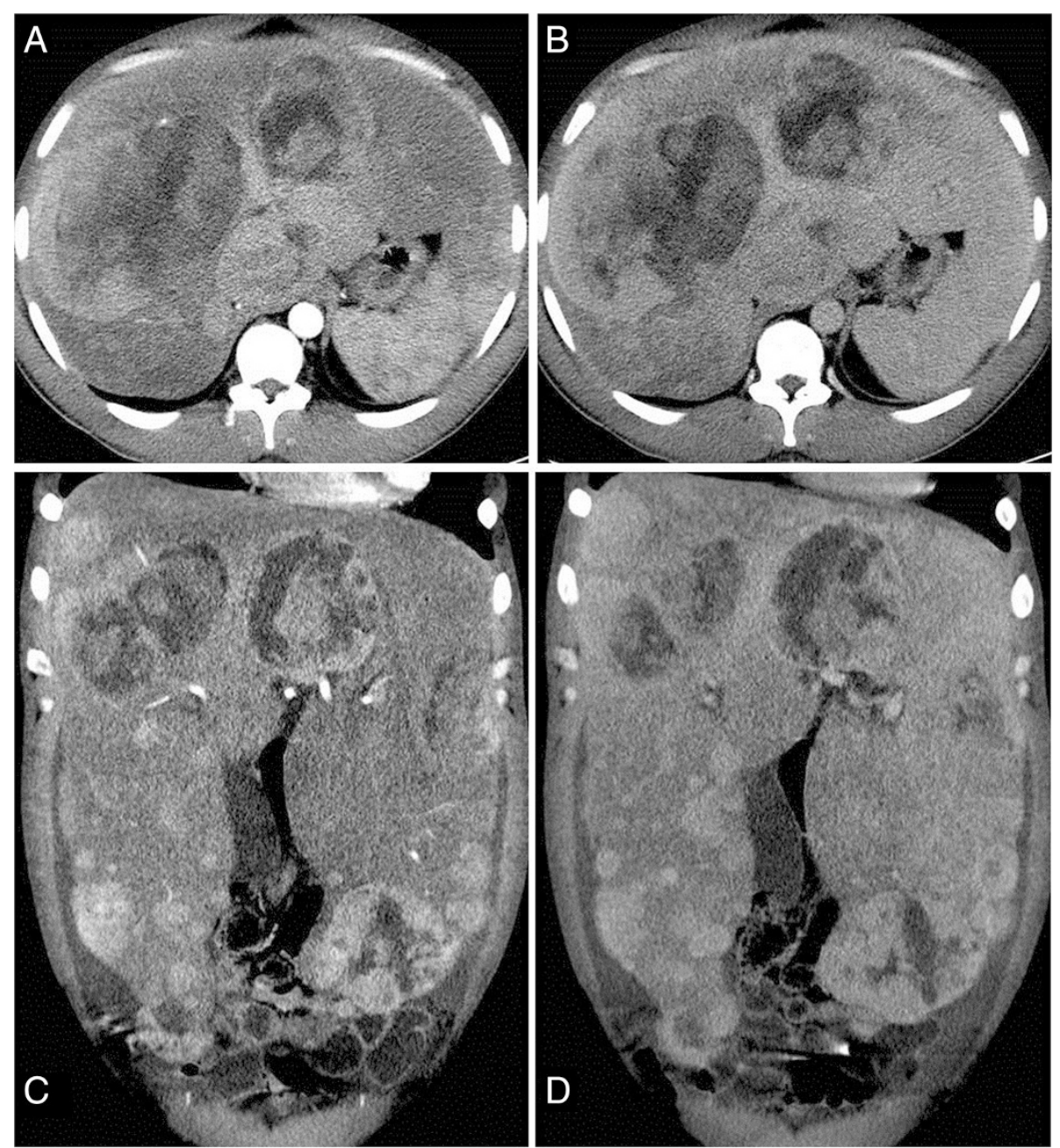

Fig. 3 Contrast enhanced computed tomography in arterial $(\mathbf{a}, \mathbf{c})$ and portalvenous phase $(\mathbf{b}, \mathbf{d})$ : Highly enlarged liver with curved borders secondary to multiple parenchymatous lesions throughout all liver segments, with arterial enhancement and no substantial wash-out during portalvenous phase. The large lesion in right lobe up to $16 \mathrm{~cm}$ appeared inhomogeneous with peripheral enhancement and non-enhancing, necrotic areas in the center. Intrahepatic vena cava and right liver vein were completely compressed by nodular tumors in the caudate lobe and the large lesion in the right lobe

and immunohistochemistry now clearly confirmed the diagnosis of a hepatocellular carcinoma (Fig. $4 \mathrm{~d}$; $\beta$-catenin $20 \%$ nuclear positive (Fig. 4a), glutamine synthetase cytoplasmic positive (Fig. 4b), androgen-receptor nuclear positive (Fig. 4c) and focal CD34 positive). Sequence analysis of exon 3 of the $\beta$-catenin gene was performed by PCR and subsequent Sanger sequencing as described in reference eleven and showed a hotspot mutation in codon 32 (p.D32G) [11].

\section{Treatment}

Due to the size and number of the lesions, there was no option for surgical resection. The distinction of all tumor nodules into HCAs and hepatocellular carcinomas was impossible, but overall HCC burden was considered to be out of the Milan criteria [12]. The multidisciplinary tumor board at Medical School Hannover initially recommended chemoembolization, which was however declined by the patient. He therefore returned home, where subsequently a liver transplantation was performed without any complications. The explanted liver showed a mass of $8 \mathrm{~kg}$. 27 months after transplantation he is in excellent condition without any signs of metastasis or local recurrence. He is not taking AAS anymore.

\section{Discussion}

We report a case of a young professional bodybuilder with self-administration of high-doses of anabolic androgenic steroids (AAS) for at least 6 years who developed a hepatocellular carcinoma (HCC) without metastasis or alpha-fetoprotein elevation. In this case, the hepatocellular carcinoma was embedded in multiple hepatocellular adenomas (HCA). 


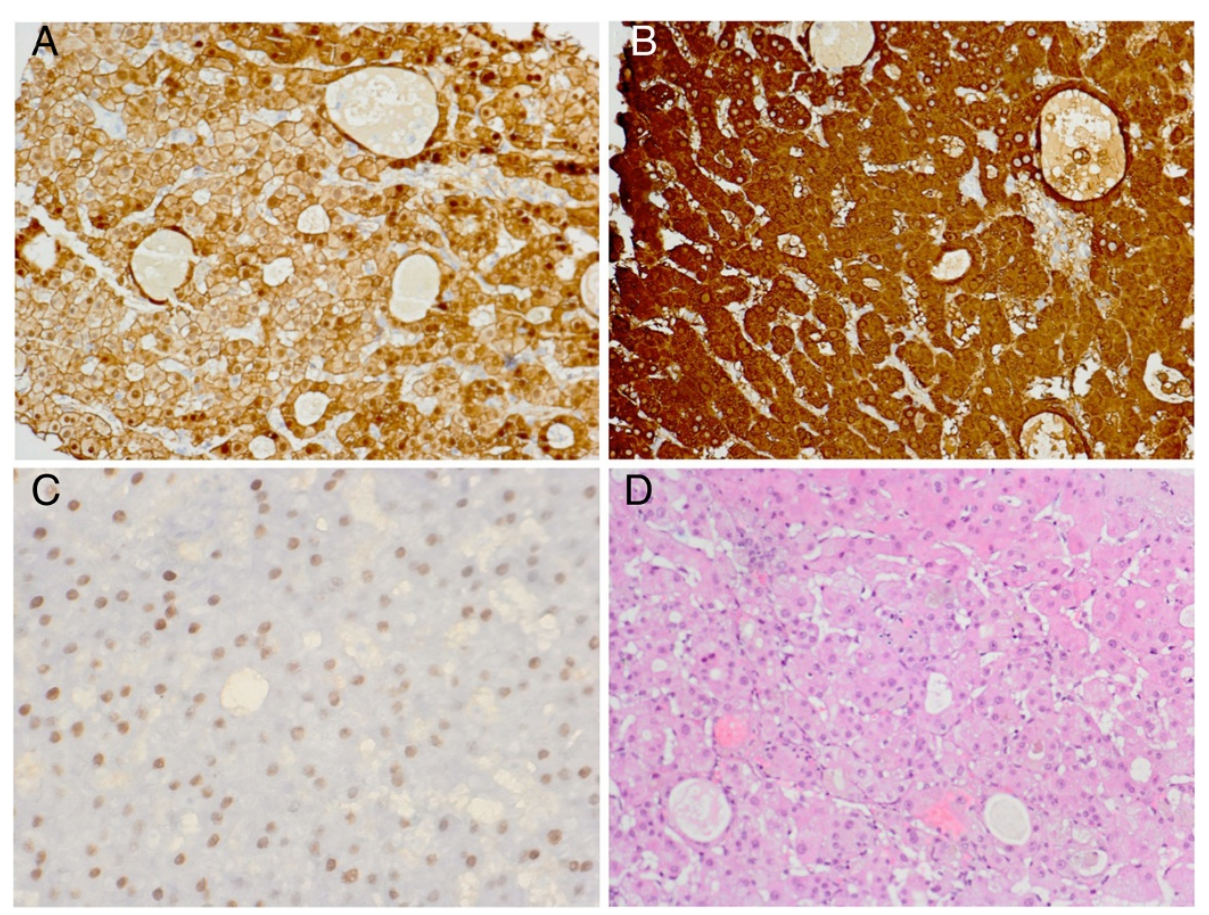

Fig. 4 Liver biopsy: Small solid and glandular associations of hepatocytes without bile duct epithelia. Reticulin fiber network focally obtained. The hepatocytes had markedly enlarged nuclei with large nucleoli with coarse structure of chromatin. Iron and rhodanine negative. Immunohistochemistry: Beta-catenin $20 \%$ nuclear positive (a; 80:1) and glutamine synthetase cytoplasmic positive (b; 160:1), hepatocytes with nuclear positivity for androgen-receptors (c; 140:1). Molecular Cytogenetics: Aneuploidy of chromosome 1 (CEP1) and 8 (CEP). Diagnosis: The results of conventional histology, molecular biology and immunohistochemistry recommended HCC G1 (d; HE stain 140:1). Comment: Simply by Cytology (FNP) a detection of HCC G1 is quite difficult. There were no bridges or cell atypia, on the other hand, histology showed more criteria for HCC G1

AAS such as testosterone and its derivates are favored in endurance and strength sports as well as in bodybuilding, often in combination with other medication like diuretics and insulin. The most popular oral products especially stanozolol, methandrostenolone and nandrolone have a high first-pass in the liver and have been reported to induce significant toxicity including intrahepatic structural changes with cholestasis and benign and malignant tumors.

It has been reported, that steroids induce HCA with potential malignant transformation into carcinoma. As described for colorectal-carcinoma, there could be an adenoma-carcinoma sequence [13]. In our case, it is difficult to distinguish whether the HCC developed de novo or within the multiple HCAs. Several biopsies from multiple tumor nodules were required to ascertain the diagnosis of HCC. The morphological distinction of HCA, focal nodular hyperplasia (FNH), macroregenerative nodules from well-differentiated HCC can be challenging [14].

Malignant transformation of HCA may occur in about $4.5-9 \%$ of cases [14-17]. Exome sequencing has identified recurrent somatic activating mutations in several genes including FRK, JAK1, gp130, and $\beta$-catenin. Moreover, integrative analysis of HCAs transformed to hepatocellular carcinoma revealed that $\beta$-catenin mutation occurs as an early alteration, whereas TERT promoter mutations are associated with the last step of the adenoma-carcinoma transition [18]. HCAs with ß-catenin mutations frequently show an overexpression of $\beta$-catenin (nuclear and cytoplasmic) and glutamine synthetase as in our patient. Although HCA shows an increased prevalence in women, beta-catenin activation is more prevalent in men with consequently an increased prevalence of HCC $[19,20]$. In our case genetic analysis for $\beta$-catenin mutations showed a hotspot mutation in codon 32 of exon 3 (p.D32G).

As has been described previously, HCA showed highly variable appearance on computed tomography $(\mathrm{CT})$, magnetic resonance imaging (MRI), and contrast-enhanced ultrasound (CEUS) scans. This is reflected by the differences in the histological features [21-25]. In the CEUS, typical HCA shows an arterial hypervascularisation in the early arterial phase with a centripetal filling pattern. However this arterial enhancement pattern can also be encountered in HCC and is not pathognomonic of HCA [26]. MRI seems to be superior to other imaging modalities for the diagnosis of HCA. One study performed by Laumonier and coworkers revealed that in hepatocyte nuclear factor 1 alpha (HNF1A) -mutated and inflammatory 
HCAs characteristic MRI patterns exist, which reach a specificity of $100 \%$ and a sensitivity of $86.7 \%$ [27]. Histology is the ultimate gold standard for the diagnosis and risk stratification of HCAs [28].

Immunochemistry analysis revealed the presence of testosterone-receptors on the hepatocellular carcinoma, which might be of prognostic significance. In one study, none of the patients with androgen receptor (AR) positive HCC survived 5 years [29]. Other studies supported these findings by suggesting a negative impact of AR positivity on tumor recurrence [30]. Various clinical trials have evaluated the role of anti-androgens for the treatment of liver cancer with controversial outcome. In a systematic review, Di Maio et al. concluded that hormonal treatment should not be a part of the current management of HCC patients [31, 32].

There are different therapeutic strategies for HCC without metastasis. First of all local ablative therapies like percutaneous ethanol injection (PEI), radiofrequency ablation (RFA), transarterial chemoembolization (TACE) and radiation therapy (RT) but effectiveness depends on the number and size of the tumors. Due to the tumor burden of our patient local ablative therapies such as RFA or surgery were not possible. TACE for bridging was recommended by the tumorboard, although a clear differentiation between HCA and carcinoma was not given. This minimally- invasive method can treat multiple tumors, can be easily repeated and is well established in the treatment algorithm for patients with advanced HCC [33]. Embolization of HCA has been rarely reported, but appears to be a feasible therapeutic option [34]. Our patient refused to take this option.

In general liver transplantation is the therapy of choice for selected patients with $\mathrm{HCC}$ without the possibility of resection and extrahepatic metastasis [35]. It is known, that patients exceeding Milan criteria for liver transplantation had a higher recurrence rate and lower survival rate than complying them. But also beyond the Milan criteria but within extended University of California, San Francisco (UCSF) criteria (single tumor $<6.5 \mathrm{~cm}$, maximum of three total tumors with none $>4.5 \mathrm{~cm}$, and cumulative tumor size $<8 \mathrm{~cm}$ ) a prolonged survival can be achieved. Survival rates beyond UCSF criteria were less than $50 \%$ at 5 years [36]. Following liver transplantation, our patient is still without any signs of tumor recurrence or metastasis.

\section{Conclusion}

In this case, 6 years of chronic anabolic androgenic steroid abuse lead to HCA and HCC development with almost no normal liver tissue left. Not only bodybuilders but also trainers and physicians should be aware of the $\mathrm{HCC}$ risk when using or prescribing AAS.

\section{Consent}

Written informed consent was obtained from the patient for publication of this Case report and any accompanying images. A copy of the written consent is available for review by the Editor of this journal.

\section{Abbreviations}

AAS: Anabolic androgenic steroids; ALT: Alanine transaminase;

AR: Androgen receptor; AST: Aspartate transaminase; AFP: Alfa-fetoprotein; CEUS: Contrast-enhanced ultrasonography; CHE: Cholinesterase; CRP: C-reactive protein; CT: Computer tomography; FNA: Fine needle aspiration; FSH: Follicle stimulating hormone; GGT: Gamma-glutamyl transferase; HCA: Hepatocellular adenoma; HCC: Hepatocellular carcinoma; INR: International normalized ratio; IVC: Inferior vena cava; LDH: Lactate dehydrogenase; LH: Luteinising hormone; MDRD: Modification of diet in renal disease; MRI: Magnet resonance imaging; PCT: Procalcitonin; PEl: Percutaneous ethanol injection; RFA: Radiofrequency ablation; RT: Radiation therapy; TACE: Transarterial chemoembolization.

\section{Competing interests}

All authors listed have contributed sufficiently to the project to be included as authors, and all those who are qualified to be authors are listed in the author byline. To the best of our knowledge, no conflict of interest, financial or other, exists.

\section{Authors' contributions}

PS carried out the concept and design of the case report, responsible for the acquisition, analysis and interpretation of data and drafted the manuscript. AP was responsible for the acquisition, sonography and for the revision of the manuscript for content. HJR was responsible for the acquisition, computed tomography and for the revision of the manuscript for content. BS was responsible for the acquisition, analysis and interpretation of data, technical support and for the revision of the manuscript for content. UL was responsible for the gene mutation analysis of ß-catenin and for the revision of the manuscript for content. AS was responsible for the acquisition, technical support and for the revision of the manuscript for content. MG was responsible for the acquisition, analysis and interpretation of data, sonography and for the revision of the manuscript for content. MM was responsible for the acquisition, analysis and interpretation of data, technical support and for the revision of the manuscript for content and study supervision. AV carried out the concept and design of the case report and was responsible for the acquisition, analysis and interpretation of data, technical support and for the final revision of the manuscript for content. All authors read and approved the final manuscript.

\section{Author details}

'Department of Gastroenterology, Hepatology and Endocrinology, Medizinische Hochschule, OE 6810 Carl-Neuberg-Str. 1, 30625 Hannover, Germany. ${ }^{2}$ Department of Diagnostic and Interventional Radiology, Medizinische Hochschule Hannover, Hannover, Germany. ${ }^{3}$ Department of Pathology, Medizinische Hochschule Hannover, Hannover, Germany.

Received: 27 January 2015 Accepted: 8 May 2015

Published online: 20 May 2015

\section{References}

1. Rooks JB, Ory HW, Ishak KG, Strauss LT, Greenspan JR, Hill AP, et al. Epidemiology of hepatocellular adenoma. The role of oral contraceptive use. JAMA. 1979;242(7):644-8.

2. Nagasue $\mathrm{N}$, Ito A, Yukaya H, Ogawa Y. Androgen receptors in hepatocellular carcinoma and surrounding parenchyma. Gastroenterology. 1985;89(3):643-7.

3. Farges O, Ferreira N, Dokmak S, Belghiti J, Bedossa P, Paradis V. Changing trends in malignant transformation of hepatocellular adenoma. Gut. 2011;60(1):85-9.

4. Johnson FL, Lerner KG, Siegel M, Feagler JR, Majerus PW, Hartmann JR, et al. Association of androgenic-anabolic steroid therapy with development of hepatocellular carcinoma. Lancet. 1972;2(7790):1273-6.

5. Labrune $P$, Trioche $P$, Duvaltier I, Chevalier P, Odievre M. Hepatocellular adenomas in glycogen storage disease type I and III: a series of 43 patients and review of the literature. J Pediatr Gastroenterol Nutr. 1997;24(3):276-9.

6. Velazquez I, Alter BP. Androgens and liver tumors: Fanconi's anemia and non-Fanconi's conditions. Am J Hematol. 2004;77(3):257-67. 
7. Gorayski P, Thompson CH, Subhash HS, Thomas AC. Hepatocellular carcinoma associated with recreational anabolic steroid use. Br J Sports Med. 2008;42(1):74-5. discussion 75

8. Hernandez-Nieto L, Bruguera M, Bombi J, Camacho L, Rozman C. Benign liver-cell adenoma associated with long-term administration of an androgenic-anabolic steroid (methandienone). Cancer. 1977:40(4):1761-4.

9. Socas L, Zumbado M, Perez-Luzardo O, Ramos A, Perez C, Hernandez JR, et al. Hepatocellular adenomas associated with anabolic androgenic steroid abuse in bodybuilders: a report of two cases and a review of the literature. Br J Sports Med. 2005:39(5):e27.

10. Hardt A, Stippel D, Odenthal M, Holscher AH, Dienes HP, Drebber U. Development of hepatocellular carcinoma associated with anabolic androgenic steroid abuse in a young bodybuilder: a case report. Case Reports Pathol. 2012;2012:195607

11. Huss S, Nehles J, Binot E, Wardelmann E, Mittler J, Kleine MA, et al. beta-catenin (CTNNB1) mutations and clinicopathological features of mesenteric desmoid-type fibromatosis. Histopathology. 2013;62(2):294-304.

12. Mazzaferro V, Regalia E, Doci R, Andreola S, Pulvirenti A, Bozzetti F, et al. Liver transplantation for the treatment of small hepatocellular carcinomas in patients with cirrhosis. N Engl J Med. 1996;334(11):693-9.

13. Dombrowski F, Flaschka C, Klotz L, von Netzer B, Schulz C, Lehnert H, et al. Hepatocellular neoplasms after intrahepatic transplantation of ovarian fragments into ovariectomized rats. Hepatology. 2006:43(4):857-67.

14. Fischer SE. Hepatocellular carcinoma arising in hepatic adenoma: diagnostic and management implications. Diagn Histopathology. 2014;20(6):257-61.

15. Kim DH, Kim SU, Nam DH, Choi YJ, Park SM, Lee CK, et al. A case of hepatocellular carcinoma within hepatocellular adenoma in a non-cirrhotic male. Korean J Intern Med. 2009;24(2):147-52.

16. Ronald M, Woodfield J, McCall J, Koea J. Hepatic adenomas in male patients. HPB (Oxford). 2004;6(1):25-7.

17. Stoot JH, Coelen RJ, De Jong MC, Dejong CH. Malignant transformation of hepatocellular adenomas into hepatocellular carcinomas: a systematic review including more than 1600 adenoma cases. HPB (Oxford). 2010;12(8):509-22

18. Pilati C, Letouze E, Nault JC, Imbeaud S, Boulai A, Calderaro J, et al. Genomic profiling of hepatocellular adenomas reveals recurrent FRKactivating mutations and the mechanisms of malignant transformation. Cancer Cell. 2014:25(4):428-41.

19. Bioulac-Sage P, Rebouissou S, Thomas C, Blanc JF, Saric J, Sa Cunha A, et al. Hepatocellular adenoma subtype classification using molecular markers and immunohistochemistry. Hepatology. 2007;46(3):740-8.

20. Zucman-Rossi J, Jeannot E, Nhieu JT, Scoazec JY, Guettier C, Rebouissou S, et al. Genotype-phenotype correlation in hepatocellular adenoma: new classification and relationship with HCC. Hepatology. 2006:43(3):515-24.

21. Arrive L, Flejou JF, Vilgrain V, Belghiti J, Najmark D, Zins M, et al. Hepatic adenoma: MR findings in 51 pathologically proved lesions. Radiology. 1994:193(2):507-12.

22. Grazioli L, Federle MP, Ichikawa T, Balzano E, Nalesnik M, Madariaga J. Liver adenomatosis: clinical, histopathologic, and imaging findings in 15 patients. Radiology. 2000;216(2):395-402.

23. Hussain SM, van den Bos IC, Dwarkasing RS, Kuiper JW, den Hollander J. Hepatocellular adenoma: findings at state-of-the-art magnetic resonance imaging, ultrasound, computed tomography and pathologic analysis. Eur Radiol. 2006;16(9):1873-86.

24. Kim TK, Jang HJ, Burns PN, Murphy-Lavallee J, Wilson SR. Focal nodular hyperplasia and hepatic adenoma: differentiation with low-mechanicalindex contrast-enhanced sonography. AJR Am J Roentgenol. 2008;190(1):58-66.

25. Psatha EA, Semelka RC, Armao D, Woosley JT, Firat Z, Schneider G Hepatocellular adenomas in men: MRI findings in four patients. J Magn Reson Imaging. 2005;22(2):258-64.

26. Claudon M, Dietrich CF, Choi Bl, Cosgrove DO, Kudo M, Nolsoe CP, et al. Guidelines and good clinical practice recommendations for Contrast Enhanced Ultrasound (CEUS) in the liver - update 2012: A WFUMB-EFSUMB initiative in cooperation with representatives of AFSUMB, AIUM, ASUM, FLAUS and ICUS. Ultrasound Med Biol. 2013;39(2):187-210.

27. Laumonier H, Bioulac-Sage P, Laurent C, Zucman-Rossi J, Balabaud C, Trillaud H. Hepatocellular adenomas: magnetic resonance imaging features as a function of molecular pathological classification. Hepatology. 2008;48(3):808-18.
28. Khalili K, Kim TK, Jang HJ, Haider MA, Khan L, Guindi M, et al. Optimization of imaging diagnosis of $1-2 \mathrm{~cm}$ hepatocellular carcinoma: an analysis of diagnostic performance and resource utilization. J Hepatol. 2011:54(4):723-8.

29. Nagasue N, Chang YC, Hayashi T, Galizia G, Kohno H, Nakamura T, et al. Androgen receptor in hepatocellular carcinoma as a prognostic factor after hepatic resection. Ann Surg. 1989;209(4):424-7.

30. Boix L, Castells A, Bruix J, Sole M, Bru C, Fuster J, et al. Androgen receptors in hepatocellular carcinoma and surrounding liver: relationship with tumor size and recurrence rate after surgical resection. J Hepatol. 1995;22(6):616-22.

31. Di Maio M, Daniele B, Pignata S, Gallo C, De Maio E, Morabito A, et al. Is human hepatocellular carcinoma a hormone-responsive tumor? World J Gastroenterol. 2008;14(11):1682-9

32. Di Maio M, De Maio E, Morabito A, D'Aniello R, De Feo G, Gallo C, et al. Hormonal treatment of human hepatocellular carcinoma. Ann N Y Acad Sci. 2006;1089:252-61.

33. Llovet JM, Real MI, Montana X, Planas R, Coll S, Aponte J, et al. Arterial embolisation or chemoembolisation versus symptomatic treatment in patients with unresectable hepatocellular carcinoma: a randomised controlled trial. Lancet. 2002;359(9319):1734-9.

34. Kim Yl, Chung JW, Park JH. Feasibility of transcatheter arterial chemoembolization for hepatic adenoma. J Vasc Interv Radiol. 2007;18(7):862-7.

35. Murray KF, Carithers Jr RL. Aasld: AASLD practice guidelines: evaluation of the patient for liver transplantation. Hepatology. 2005;41(6):1407-32.

36. Duffy JP, Vardanian A, Benjamin E, Watson M, Farmer DG, Ghobrial RM, et al. Liver transplantation criteria for hepatocellular carcinoma should be expanded: a 22-year experience with 467 patients at UCLA. Ann Surg. 2007:246(3):502-9. discussion 509-511.

\section{Submit your next manuscript to BioMed Central and take full advantage of:}

- Convenient online submission

- Thorough peer review

- No space constraints or color figure charges

- Immediate publication on acceptance

- Inclusion in PubMed, CAS, Scopus and Google Scholar

- Research which is freely available for redistribution 